\title{
Наука
}

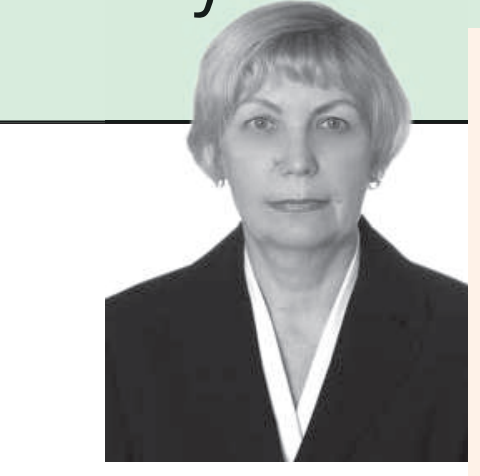

Н.Х. ВАФИНА

Доктор экон. наук, профессор кафедры «Микроэкономика» Финансового университета при Правительстве Российской Федерации.

E-mail: wafina@mail.ru
$\mathrm{C}$

учетом противоречивого характера деятельности транснационального предпринимательства становится актуальным развитие механизмов мониторинга, системного анализа, контроля процессов транснационализации производства с позиции обеспечения экономической безопасности. В данной статье рассмотрены особенности государственного воздействия на транснациональный бизнес для реализации национальных экономических интересов. Выделены условия эффективного регулирования процессов транснационализации производства в условиях усиления неустойчивости экономического развития.

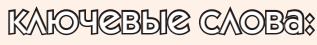

баланс интересов, государственное воздействие, национальная экономическая безопасность, транснациональное предпринимательство.

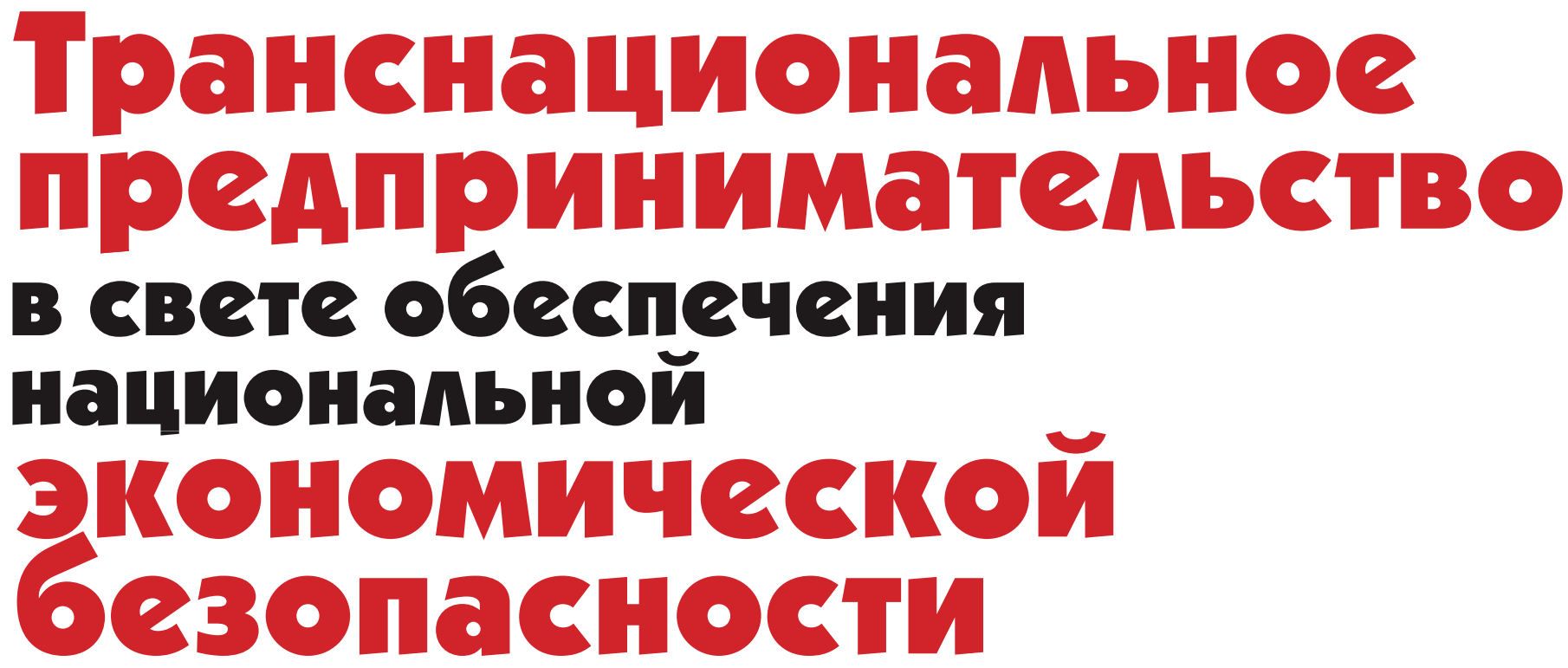

\section{(Теоретические аспекты)}

\section{Понятие баланса интересов}

Изучение закономерностей воздействия государств на транснациональный бизнес целесообразно строить на основе анализа базового понятия баланса интересов. Синтетичность данного понятия, отражающего роль сознатель- мулирует его применение для исследования мер воздействия со стороны правительств на транснациональное предпринимательство как принимающих стран, так и стран происхождения транснациональных бизнес-структур. Это понятие позволяет отразить многоуровневость, многоаспектность и динамизм современного социально-экономического развития. Необходимо 
отметить эволюцию в толковании категории национальных интересов, выразителями которых выступают государства, и определить принципы достижения баланса национально-государственных интересов и интересов транснационального капитала.

\section{Транснационаиьный \\ бизнес \\ и национапьные \\ экономические \\ интересы}

В различных странах и в разные исторические периоды национальные интересы понимались неодинаково. Для одних государств национальный интерес - это элемент интернационального единства рабочего класса в борьбе (вплоть до вооруженной) против международного капитала (позиция пролетарского интернационализма), для других стран национальные интересы отождествляются с корпоративными и личными интересами финансово-промышленных олигархов (позиция рыночного фундаментализма). И в том и в другом случае часть общества выступает с намерением выражать соответствующие интересы от лица всего населения. Возможны и другие подходы к определению национальных интересов, которые получили отражение в литературных источниках, посвященных данной проблематике $[2,3]$. В настоящее время наибольшее распространение получает точка зрения, согласно которой национальный интерес - это возможность обеспечить на практике сочетание интересов личности, общества и государства. При этом государство должно выступить в качестве гаранта реализации права общества и каждого человека на развитие и повышение благосостояния. Это обусловливает проблему отстаивания национального интереса в противоборстве с групповыми интересами или частным эгоизмом.

В современных условиях возможности развития в значительной степени определяет экономический компонент, он выступает ключевым национальным приоритетом любой страны. Однако при решении экономических проблем нельзя упускать из виду вопросы экономической безопасности, социально-культурного развития, накопления духовных ценностей, которые составляют равноправные компоненты национального интереса. Наибольших успехов добились страны, учитывающие необходимость обеспечения баланса экономических, экологических, социально-культурных элементов при формулировании и реализации национальных интересов.
Кроме того, следует отметить, что в современном глобализирующемся мире ориентиры национального развития зависят не только от внутренних факторов, но и от интенсивных экономических, технологических, политических трансформаций, влияющих на мировое хозяйство. Поэтому с нарастанием проявлений тенденции глобализации реализация национальных интересов становится невозможной без учета общемировых закономерностей развития.

Процессы транснационализации производства, выступающей важнейшим направлением глобализации, существенно расширяют сферу национальных интересов стран. Формирование отечественных транснациональных бизнесструктур ставит на повестку дня вопросы отстаивания национальных интересов за рубежом на всех стадиях: согласования порядка вхождения (или допуска) национальных производителей в зарубежную экономику, обеспечения гарантий поддержки развития и укрепления зарубежных позиций национальной экономики на основе стимулирования транснационализации отечественного производства и т. п.

Если раньше ряд государств проявлял негативное отношение к деятельности иностранных транснациональных корпораций (ТНК), то теперь их работа получает одобрение, началась даже конкуренция за привлечение транснациональных капиталов, так как постепенно сложились и развиваются механизмы достижения баланса интересов всех сторон, охваченных процессами транснационализации производства. Это не означает, что диктат с позиции силы остался в прошлом и утратил свое значение. Тем не менее объективные закономерности развития (закон продуктивной конкуренции, интернационализация хозяйственной жизни и др.) обусловливают тенденцию к расширению конструктивного и взаимовыгодного сотрудничества национальных государств и транснационального бизнеса.

Многоаспектная задача достижения баланса интересов решается в режиме диалога. Поэтому в современных условиях важное значение придается оформлению диалогового начала в механизме взаимодействия транснациональных бизнес-структур и правительств, реализующих наступательные и оборонительные функции государственных органов власти в обеспечении национальных интересов. Важную роль играет умение находить такие национальные решения, которые сопоставлялись бы со стандартами мирового рынка и вместе с тем предусматривали бы прежде всего защиту национальной безопасности.

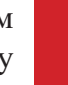




\section{Значение обеспечения национальной безопасности и повышения конкурентоспособности}

Как известно, безопасность - это отсутствие опасности или наличие возможности надежно защититься от нее. Опасным можно считать воздействие транснационального бизнеса на экономику страны базирования или принимающей страны, которое может привести к дестабилизирующему результату, ущемляющему интересы личности, общества и государства.

А. Урсул отмечает, что «безопасность... начинает по-новому осознаваться, становясь жизненно важной ценностью. Многие ценности XX века оказываются менее значительными, чем ценности, связанные с безопасностью, и поэтому среди ценностей XXI века, да и, возможно, всего III тысячелетия безопасность оказывается едва ли не самой значимой. Рост значимости безопасности как ценности и критерия развития связан с осознанием комплексного и системного подхода к проблеме безопасности, что проявляется в разработке различных концепций, доктрин, хартий и тому подобное» [4]. В настоящее время действует целостная совокупность достаточно простых и надежных параметров национальной безопасности - целевых индикаторов, а точнее, их отклонений от целевых значений.

Совершенно очевидно, что критерий национальной безопасности является приоритетным при формировании системы мер государственного регулирования процессов транснационализации производства. На наш взгляд, разработка этой системы целесообразна в рамках ориентации на интенсивно-коэволюционный способ развития, использование которого станет возможным не в результате увеличения привлекаемых ресурсов и энергии, а благодаря их более эффективному применению на базе инновационно ориентированных стратегий. Предполагается соблюдение нормативов изъятия невозобновляемых ресурсов и переход в основном на использование возобновляемых ресурсов. Это означает, что механизмы, связанные с формированием интенсивно-коэволюционного способа развития и пока являющиеся внешними, чуждыми современной экономике, должны превратиться в ее внутренние механизмы саморазвития. Среди условий, обеспечивающих переход к этому новому типу развития, можно выделить:

- обязательность экологической экспертизы всех хозяйственных проектов; устойчивого функционирования и развития экосистем;

- обязательность полной компенсации нанесенного ущерба со стороны виновника возникновения экологически опасной ситуации, эффективная реализация принципа «загрязнитель платит»;

- обеспечение свободного доступа к полной и достоверной экологической информации, создание необходимых для этого баз данных и коммуникаций.

Такой подход в большей степени будет соответствовать обеспечению первого критерия национальной безопасности, в том числе экономической, экологической, энергетической безопасности.

Другим важнейшим критерием, который может рассматриваться как аналитический инструментарий для оценки эффективности государственного регулирования транснационального бизнеса, служит повышение национальной конкурентоспособности. Конкурентоспособность страны является политико-экономическим понятием, которое характеризует способность экономических структур и институтов страны эффективно координировать хозяйственную деятельность в рамках мировой экономики с целью обеспечить долгосрочный экономический рост и повышение жизненного уровня граждан [1].

На наш взгляд, стратегическая значимость повышения конкурентоспособности страны позволяет оценить эффективность мер, предпринимаемых государством для формирования предпосылок создания новых конкурентных преимуществ фирм, находящихся под его юрисдикцией, для стимулирования высокопроизводительных видов деятельности зарубежных ТНК на своей территории. При этом необходимо отметить изменение основного критерия привлекательности прямых инвестиций: вместо увеличения объема добавленной стоимости повышение конкурентоспособности местных ресурсов и мощностей в долгосрочной перспективе. Таким образом, именно с позиций обеспечения роста конкурентоспособности страны и гарантирования ее безопасности следует подходить к определению государственной политики в целом и важнейшей ее составляющей механизма регулирования процессов транснационализации производства.

\section{ГосУАарственное возАействие на транснационапьный бизнес}

В самом общем виде задачи государственного воздействия на транснациональный бизнес можно сформулировать следующим образом: 
для достижения долгосрочного роста национальной экономики, повышения жизненного уровня населения при минимизации отрицательных эффектов путем использования потенциала транснационального производства. Важно вовремя обнаружить нарастание негативных тенденций и вводить в действие новые компенсаторные механизмы в форме законодательных, экономических или административных регуляторов.

По мере повышения национальной конкурентоспособности практика применения ограничительных мер по отношению к зарубежным ТНК сокращается, вводимые стимулирующие методы предполагают отсутствие дискриминации в отношении отдельных экономических субъектов, в том числе по критерию национальной принадлежности. Хотя системы поощрения в разных странах различны, но есть нечто общее: эффективная система стимулирования должна обладать такими характеристиками, как гибкость, объективность, простота, последовательность административной политики государства и скорость реализации намеченных мер.

Правительства стран признают свою ответственность за предсказуемость принимаемых ими решений, то есть обязуются играть по правилам. Предпочтение отдается созданию постоянно действующих механизмов взаимоотношений государства и транснационального бизнеса, в таком качестве рассматриваются:

- законы и соответствующие им постановления исполнительной власти;

- деловая и административная практика, которая не противоречит законам и постановлениям.

Такова общая схема модели взаимоотношений государств с транснациональными структурами, конкретные меры и средства, используемые в ней, зависят от уровня развития экономики, степени еe интернационализации и роли внутрифирменных связей ТНК (интернационализации).

Воздействие на транснациональный бизнес реализуется в рамках общей экономической политики, в том числе структурной (промышленной, научно-технической) и социальной, предусматривает совокупность мер в инвестиционной, производственной, финансовой, кредитно-денежной и внешнеэкономической сферах. Макроэкономическое регулирование, устанавливающее общие правила и параметры хозяйствования для организаций всех типов, дополняется системой мер, регламентирующих поведение транснационального бизнеса. В частности, должны быть четко определены области применения режима наибольшего благоприятствования и националь- ного режима (создание для иностранных ТНК не менее благоприятных условий по сравнению с существующими для отечественных предпринимателей в сфере регулирования производства, продажи товаров, оказания услуг, инвестирования, перемещения граждан). В ряде случаев, исходя из национальных интересов, возможно введение обоснованных ограничений, например на передачу в эксплуатацию зарубежным компаниям месторождений стратегических природных ресурсов, телекоммуникаций, транспортных и товаропроводящих сетей и т. п.

Государственное регулирование предполагает соблюдение ряда положений о контроле трансфертного ценообразования, налогообложении, обеспечении более широкого раскрытия информации о деятельности ТНК. Существует достаточно разработанная система модельного подхода к решению, например, проблемы устранения двойного налогообложения, данная система явилась результатом международных переговоров и т. п. Цель - получение всеми заинтересованными странами разумных налоговых доходов, правильное определение налоговых обязательств ТНК на основе адекватной политики трансфертного ценообразования осуществляется в ходе международной нормотворческой деятельности на двустороннем, региональном, национальном и глобальном уровнях.

Важнейшим условием эффективного воздействия на процессы транснационализации производства является развитие транспарентности, то есть обеспечения доступности, прозрачности и достоверности информации. Имеется в виду транспарентность не только политики фирм, но и правительственной политики в области налогообложения, тарифов, перевода средств и т. п. Кроме того, с учетом проблемы взяточничества в указанных сферах нередко возникают серьезные проблемы обеспечения транспарентности отношений между ТНК и правительствами, когда речь идет о практике трансфертного ценообразования и других направлениях регулирования транснациональной деятельности. Следовательно, в современных условиях обеспечение транспарентности становится предпосылкой достижения баланса интересов национальных государств и транснационального бизнеса.

Наряду с деятельностью контрольных органов немаловажное значение имеет привлечение широкой общественности к мониторингу деятельности госаппарата и бизнеса. На наш взгляд, для достижения этой цели целесообразно изучить опыт реального общественного контроля в странах с развитой демократией. Например, стоит обратить внимание на британскую систему 
контроля за деятельностью госорганов. Здесь заметную роль играют различные неправительственные обзоры, исследования и разработки по конкретным направлениям деятельности администрации (госаппарата). Такие обзоры составляются на основе широкодоступных статистических и других аналитических материалов о работе госорганов и регулярно выпускаются университетами, общественными организациями. Они дают дополнительную возможность конструктивного анализа отдельных направлений политики правительства, обеспечивают общественности условия для непосредственного участия в контроле за его деятельностью.

Систематическая отчетность исполнительной власти перед представителями общественности (парламентом), а также открытость ее деятельности средствам массовой информации и широкой общественности снижают риск безответственности принимаемых решений. Это позволяет предотвращать использование рычагов государственной власти в процессе накопления капитала приближенными к госаппарату коммерческими структурами. Кроме того, независимая оценка правительственных решений дает возможность выявлять дополнительные альтернативы, разрабатывать наиболее приемлемые варианты, усовершенствовать существующие системы государственного управления.

Новые возможности реорганизации собственно органов управления и процессов управляющего воздействия на экономику, в том числе на процессы транснационализации производства, связаны с развитием компьютеризированных систем информации. С помощью современных информационных технологий совершенствуется отчетность государственных служб, возрастает оперативность их деятельности. Государство может формировать новые процессы, на основе применения электронных средств обеспечивающие участие граждан в слушаниях по поводу возможных начинаний государственных органов, генерации идей по важнейшим вопросам, включая взаимодействие $\mathrm{c}$ международным бизнесом. В этом случае демократический процесс становится более оперативным, оказывает значимое воздействие на правительственные решения, в том числе по проблемам, связанным с транснациональным предпринимательством

\section{ВЫводЫ}

Исследование развития транснационального предпринимательства с позиций обеспечения национальной безопасности позволяет сделать следующие выводы. Соблюдение национального интереса и защита национальной безопасности являются приоритетными задачами регулирования процессов транснационализации производства правительствами как принимающих стран, так и стран происхождения ТНК. Государства несут ответственность за согласованное обеспечение интересов всех субъектов экономической деятельности на своей территории в настоящее время и в перспективе. Государственные органы должны сконцентрировать свои усилия, чтобы определить правила поведения хозяйствующих субъектов, а не напрямую принуждать их к конкретным действиям.

Модели воздействия со стороны государства на транснациональный бизнес варьируют в зависимости от уровня развития тех или иных стран. Сложившиеся уникальные обстоятельства влияют на масштабы, границы, формы, инструменты государственного регулирования. Вместе с тем следует иметь в виду, что транснациональные системы воспринимают лишь те управляющие действия, которые соответствуют их внутренним закономерностям развития. Поэтому важное значение имеет постижение объективных тенденций процессов транснационализации производства, что облегчает поиск зон эффективного воздействия на них со стороны правительств принимающих стран и стран происхождения ТНК.

Потребность в активизации государственного регулирования возрастает в периоды большей неустойчивости экономического развития. У транснациональных субъектов должны формироваться соответствующие ожидания, тогда на их поведение не будут влиять случайные факторы.

Важнейшими условиями эффективного государственного воздействия на транснациональное предпринимательство являются:

- развитие транспарентности, прозрачности деятельности транснационального бизнеса и его отношений с органами государственной власти;

- оформление механизма диалога, в рамках которого будут эффективны наступательные и оборонительные функции государственного вмешательства.

Хотя новые информационные технологии являются залогом преобразований госрегулирования всех направлений развития экономики, в том числе и процессов транснационализации производства, но решение вопроса о том, как эти технологии помогут отказаться от устаревших стереотипов в государственном управлении, зависит от наличия политической воли, готовности государственного аппарата к переменам. В области законодательства государства должны не замыкаться в национальных рамках, а учиты- 
вать международные правила и нормы, постоянно сравнивая свои законы с законами других государств, особенно в области регулирования международных потоков капиталов, товаров и т. д. Иными словами, при осуществлении важнейших функций государства следует учитывать процессы, разворачивающиеся на международном уровне:

- усиление международной конкуренции в области технологии и экономики;

- перемещение предприятий за рубеж, которое приводит к усилению конкуренции между национальными юридическими пространствами.

Национальные механизмы регулирования в различных областях деятельности, в том числе процессов транснационализации производства, оказываются в той или иной мере зависимыми от наднациональных правил и норм. Таким образом, государственное воздействие на процессы транснационализации производства выступает в качестве одного из звеньев все более усложняющегося механизма, регулирующего глобальные экономические отношения.

1. Геоэкономика и конкурентоспособность России: Научно-концептуальные основы геоэкономической политики России: Научно-аналитический доклад / М. Ю. Байдаков, Н. Ю. Конина, Э. Г. Кочетов и др.; под науч. ред. Э.Г. Кочетова; Общественная академия наук геоэкономики и глобалистики. М.: Книга и бизнес, 2010. 388 с.

2. Мухин Г. Проблемы обеспечения национально-государственных интересов России в условиях трансформации международных отношений // Безопасность Евразии. 2007. №4.

3. Основы экономической безопасности (Государство, регион, предприятие, личность) / Под ред. Е. А. Олейникова. М.: ЗАО «Бизнес-школа»; «Интел-Синтез», 2011.

4. Урсул А. Безопасность и развитие: концептуально-методологические аспекты // Безопасность Евразии. 2007. №1. С. 315. 